\title{
The evolutionary ecology of testicular function: size isn't everything
}

\author{
Steven A. Ramm ${ }^{1}$ and Lukas Schärer ${ }^{2, *}$ \\ ${ }^{1}$ Evolutionary Biology, Bielefeld University, Morgenbreede 45, 33615 Bielefeld, Germany \\ ${ }^{2}$ Evolutionary Biology, Zoological Institute, University of Basel, Vesalgasse 1, 4051 Basel, Switzerland
}

\begin{abstract}
Larger testes are considered the quintessential adaptation to sperm competition. However, the strong focus on testis size in evolutionary research risks ignoring other potentially adaptive features of testicular function, many of which will also be shaped by post-mating sexual selection. Here we advocate a more integrated research programme that simultaneously takes into account the developmental machinery of spermatogenesis and the various selection pressures that act on this machinery and its products. The testis is a complex organ, and so we begin by outlining how we can think about the evolution of testicular function both in terms of the composition and spatial organisation of the testis ('testicular histology'), as well as in terms of the logical organisation of cell division during spermatogenesis ('testicular architecture'). We then apply these concepts to ask which aspects of testicular function we can expect to be shaped by post-mating sexual selection. We first assess the impact of selection on those traits most strongly associated with sperm competition, namely the number and kind of sperm produced. A broad range of studies now support our contention that post-mating sexual selection affects many aspects of testicular function besides gross testis size, for example, to maximise spermatogenic efficiency or to enable the production of particular sperm morphologies. We then broaden our focus to ask how testicular function is affected by fluctuation in sperm demand. Such fluctuation can occur over an individual's lifetime (for example due to seasonality in reproduction) and may select for particular types of testicular histology and architecture depending on the particular reproductive ecology of the species in question. Fluctuation in sperm demand also occurs over evolutionary time, due to shifts in the mating system, and this may have various consequences for testicular function, for example on rates of proliferation-induced mutation and for dealing with intragenomic conflict. We end by suggesting additional approaches that could be applied to study testicular function, and conclude that simultaneously considering the machinery, products and scheduling of spermatogenesis will be crucial as we seek to understand more fully the evolution of this most fundamental of male reproductive traits.
\end{abstract}

Key words: meiosis, relative testis size, spermatogenesis, spermatogonial stem cells, sperm competition, sperm morphology, testicular architecture, testis function.

\section{CONTENTS}

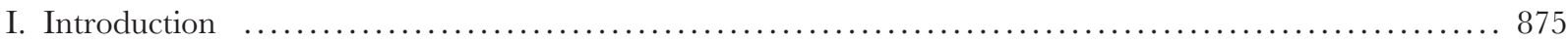

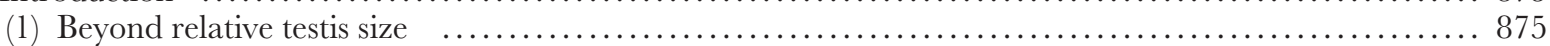

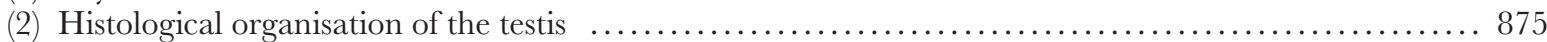

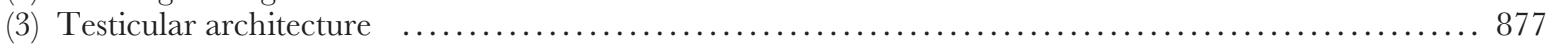

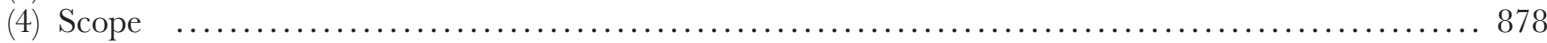

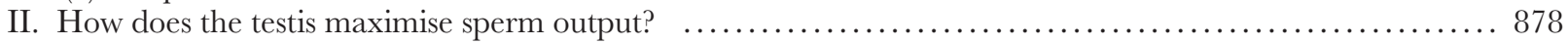

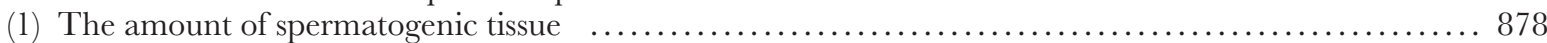

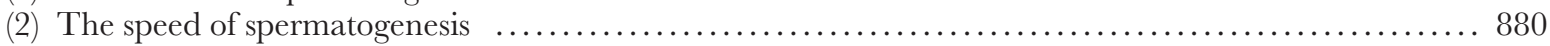

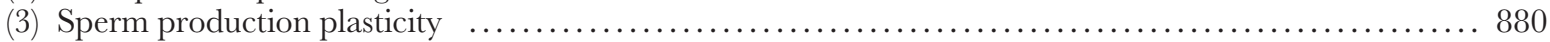

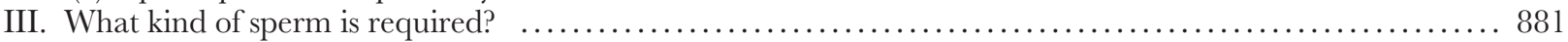

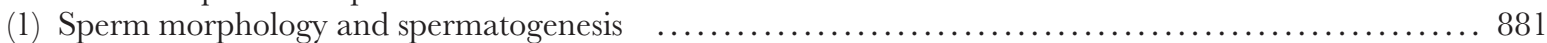

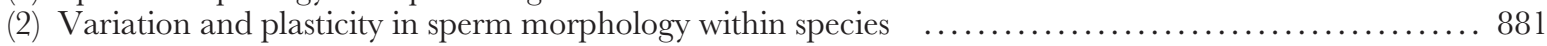

* Author for correspondence (Tel: +41 61267 0366; E-mail: lukas.scharer@unibas.ch). 


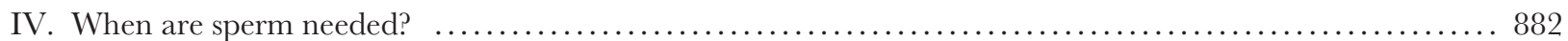

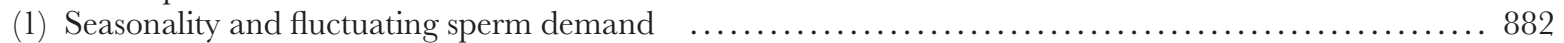

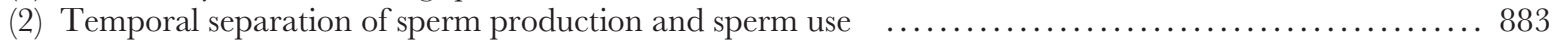

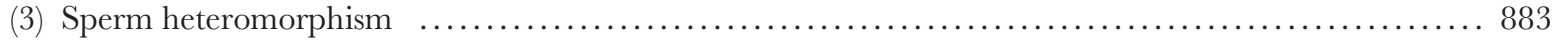

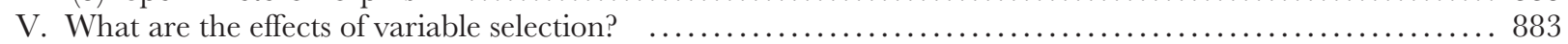

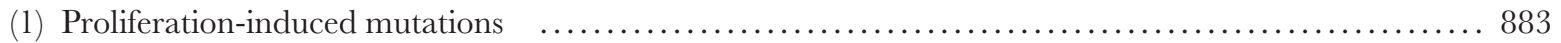

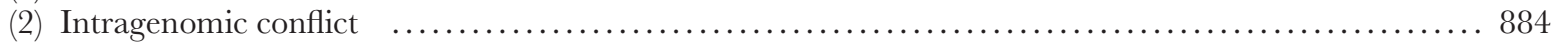

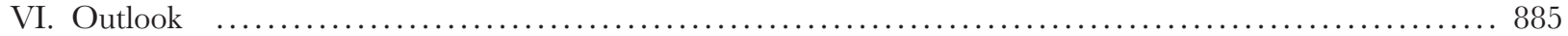

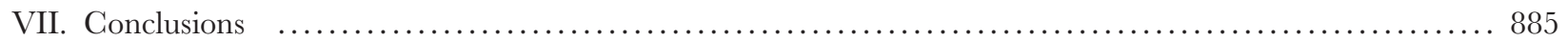

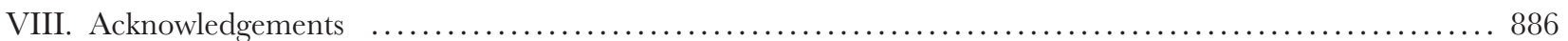

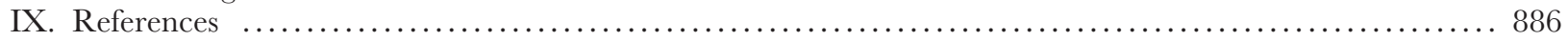

\section{INTRODUGTION}

\section{(1) Beyond relative testis size}

Despite its importance for reproduction and fertility, we still know surprisingly little about the evolutionary ecology of testicular function. While reproductive and developmental biologists are making substantial progress in understanding spermatogenesis in a number of model species (e.g. Fuller, 1998; Kerr, Loveland \& O'Bryan, 2006; White-Cooper, Doggett \& Ellis, 2009; Cheng \& Mruk, 2010; White-Cooper \& Bausek, 2010), we often lack an ecological and evolutionary context in which to interpret these findings. Conversely, we generally know little about spermatogenesis in the diverse range of non-model organisms that tend to be the subject of evolutionary and ecological research on male reproductive investment and sperm competition. In part this results from a strong emphasis in the sperm competition literature on the size of the testes relative to body size (i.e. 'relative testis size'; a glossary of key terms is provided in Table 1) as a proxy measure of male investment in sperm production. We begin by explaining the rationale for such an approach.

Mathematical sperm competition models attempt to predict how males should optimally allocate a fixed reproductive energy budget between ejaculate production versus effort in gaining matings (e.g. Parker et al., 1996, 1997; Parker, 1998; Parker \& Ball, 2005; Parker, Lessells \& Simmons, 2013). In broad terms, these models predict that as the level of sperm competition in a population increases, so too should the proportion of resources males expend on ejaculate production. In order to test this now well-supported prediction, many comparative studies have used relative testis size as a means of capturing variation between species in sperm production, assuming that relative testis size and sperm production are strongly correlated (reviewed in Parker et al., 1997; Parker \& Pizzari, 2010). In addition, experimental evolution studies in dung flies, fruit flies and dung beetles have demonstrated divergence in testis size under different sperm competition conditions (Hosken \& Ward, 2001; Pitnick et al., 2001; Simmons \& GarciaGonzalez, 2008; but see Crudgington et al., 2009; Firman \& Simmons, 2010). These comparative and experimental evolution studies thus provide powerful support for sperm competition theory.
However, we emphasise that in most cases what was measured in these and similar studies is not sperm (or ejaculate) production rate per se, which is the trait that models assume to be the true target of selection under purely numerical sperm competition, but rather an assumed proxy for sperm production, i.e. relative testis size. The assumption that relative testis size strongly correlates with sperm production may often be justified as a first approximation, and many interesting insights have been gained from the use of this proxy measure. But we feel that many researchers tend to be overly confident about the strength of this relationship, which has been properly investigated for only a few study organisms. So whilst relative testis size will likely continue to be a useful means of estimating male investment in sperm production in many cases, we wish to highlight in this review that focusing solely on this trait risks ignoring other potentially adaptive features of testicular function affected by sperm competition and thus might ultimately hinder our attempts to understand how sexual selection shapes the evolution and function of this fundamentally important organ. We therefore advocate a more integrated research programme that explicitly takes into account the biology of spermatogenesis, in terms of its histological organisation within the testis and the logical architecture of cell division supporting testicular maintenance and gamete formation. Because of the importance of these concepts to the remainder of the review, in the following two sections we first provide a general description of what we mean by testicular histology and testicular architecture.

\section{(2) Histological organisation of the testis}

The testis is an epithelial tissue incorporating both germ cells and somatic cells. Depending on the organismal group, the contribution of the latter can either be fairly minimal or can comprise a whole range of different cell types that variably provide an envelope, a vascular system, endocrine function (e.g. Leydig cells), and a supportive cellular environment (e.g. Sertoli cells), in which the germ cells divide and differentiate in the process of spermatogenesis. The germline cells can be subdivided according to the three different stages of spermatogenesis, as shown in Fig. 1A: (i) a pre-meiotic or spermatocytogenesis stage, during which spermatogonia (i.e. testicular stem cells, depicted in green) undergo asymmetric 
Table 1. Glossary of key terms for exploring the evolutionary ecology of testicular function

\begin{tabular}{|c|c|}
\hline Term & Definition \\
\hline BrdU & $\begin{array}{l}\text { Bromodeoxyuridine, a thymidine analogue that can be administered to and becomes incorporated into } \\
\text { proliferating cells during S-phase (DNA replication). These cells can later be visualised using } \\
\text { immunocytochemistry, allowing a pool of dividing cells to be tracked over time. }\end{array}$ \\
\hline Relative testis size & $\begin{array}{l}\text { Widely employed as a measure of male investment in sperm production, and as a likely index of sperm } \\
\text { competition level (but see main text). Can be calculated in various ways, e.g. as a pure percentage of } \\
\text { body volume occupied by the testis, or preferably as residual testis mass (or some index derived from it) } \\
\text { that takes into account the scaling of testis size with body size. }\end{array}$ \\
\hline Spermatogenesis & The process through which male gametes are produced in the testis (see Fig. 1). \\
\hline Spermatogenesis kinetics & $\begin{array}{l}\text { The study of the timing of spermatogenesis, which in vertebrates involves studying the predictable spatial } \\
\text { arrangements of germ cells within the seminiferous epithelium as spermatogenesis proceeds, enabling } \\
\text { the calculation of the seminiferous epithelium cycle length (SECL), from which the duration of } \\
\text { spermatogenesis can be estimated. }\end{array}$ \\
\hline Spermatogenic efficiency & $\begin{array}{l}\text { Various definitions exist, all of which capture aspects of how productive the testis is, e.g. in terms of }(i) \text { the } \\
\text { amount of spermatogenic tissue for a given unit testis size, }(i i) \text { the amount of sperm produced by a given } \\
\text { size unit of spermatogenic tissue, or (iii) the number of mature spermatozoa that result from a } \\
\text { spermatogonial cell division or, in vertebrates, per Sertoli cell. }\end{array}$ \\
\hline Spermatogenic tissue & $\begin{array}{l}\text { Not all of the testis is involved in making sperm, so a distinction is drawn between spermatogenic (i.e. } \\
\text { sperm-producing) tissue and non-spermatogenic tissue (sometimes called interstitial tissue) - see Fig. } 1 \\
\text { for explanation of the main cell types found within the testis. }\end{array}$ \\
\hline Spermatozoa/sperm & The mature male gametes, which develop from: \\
\hline Spermatogonia & $\begin{array}{l}\text { Testicular stem cells that undergo asymmetric mitotic divisions in order to maintain a self-renewing stem } \\
\text { cell population and produce cells committed to differentiation. }\end{array}$ \\
\hline Spermatocytes & $\begin{array}{l}\text { First (or primary) spermatocytes are the end-product of mitotic expansion that then undergo two rounds } \\
\text { of meiotic cell division to produce haploid spermatids. }\end{array}$ \\
\hline Spermatids & $\begin{array}{l}\text { The haploid cells that are the end-product of meiosis, and which differentiate to become mature } \\
\text { spermatozoa. }\end{array}$ \\
\hline Sperm morphology & $\begin{array}{l}\text { Often used to be synonymous with sperm design and sperm morphometry, but we recommend that the } \\
\text { term be used as a more general term to encompass both radical qualitative variation (sperm design) and } \\
\text { more nuanced quantitative variation (sperm morphometry): }\end{array}$ \\
\hline Sperm design & $\begin{array}{l}\text { Radical qualitative changes in (usually) multiple aspects of sperm morphology. Exhibits wide } \\
\text { interspecific variation. }\end{array}$ \\
\hline Sperm morphometry & $\begin{array}{l}\text { Quantitative variation in sperm parameters, such as changes in the relative dimensions of different } \\
\text { sperm components (e.g. head, midpiece, tail, etc.). Exhibits wide interspecific variation, and often also } \\
\text { exhibits considerable intraspecific variation. }\end{array}$ \\
\hline Testicular histology & The morphological organisation of cells within the testis - see Section I.2. \\
\hline Testicular architecture & The logical organisation of cells within the testis and their pattern of division - see Section I.3. \\
\hline
\end{tabular}

mitotic divisions, thus maintaining a self-renewing stem cell population and producing daughter cells committed to differentiation and often going through several rounds of symmetric mitotic divisions (mitotic expansion) resulting in first (or primary) spermatocytes (orange); (ii) a meiotic stage, during which spermatocytes undergo the two rounds of meiotic cell division to produce haploid spermatids (yellow); and (iii) a post-meiotic or spermiogenesis stage, during which spermatids undergo (often highly complex) differentiation to become mature spermatozoa (blue) (Roosen-Runge, 1977; Kerr et al., 2006; Ramm \& Stockley, 2010; White-Cooper $\&$ Bausek, 2010). The germline cells themselves are often highly organised spatially within the testis [e.g. Fig. 1B, C, although there are notable exceptions, e.g. chaetognaths (Shinn, 1997)]. Variations even on this general theme are possible, with, for example, self-renewing spermatogonia being maintained by a stochastic rather than an asymmetrical division model in mouse (Klein et al., 2010; Yoshida, 2012) or with mitosis replacing meiosis in some insects with haploid males (Normark, 2009). Moreover, within each of these stages there is wide interspecific (and sometimes intraspecific) diversity. This diversity currently lacks a comprehensive evolutionary explanation, although we argue herein that much of it has likely been shaped by post-mating sexual selection. To illustrate the kind of variation we are talking about, two examples are depicted in Fig. 1A. First, an increase in the number of rounds of mitotic cell divisions to generate first spermatocytes (more in the top half, fewer in the bottom half of the panel - see also Section I.3), could, for example, result from selection for a higher sperm production rate due to sperm competition, and would be expected to result in different ratios of cell types in a histological section of the testis. Second, selection on longer sperm cells, possibly as a result of coevolutionary changes in female reproductive tract morphology, would likely mean that each sperm takes longer to make, leading to an increase in the duration of spermiogenesis (longer in the top two sperm, shorter in the bottom two sperm). These and other aspects of testicular function affected by post-mating sexual selection are discussed in detail in Sections II and III. 


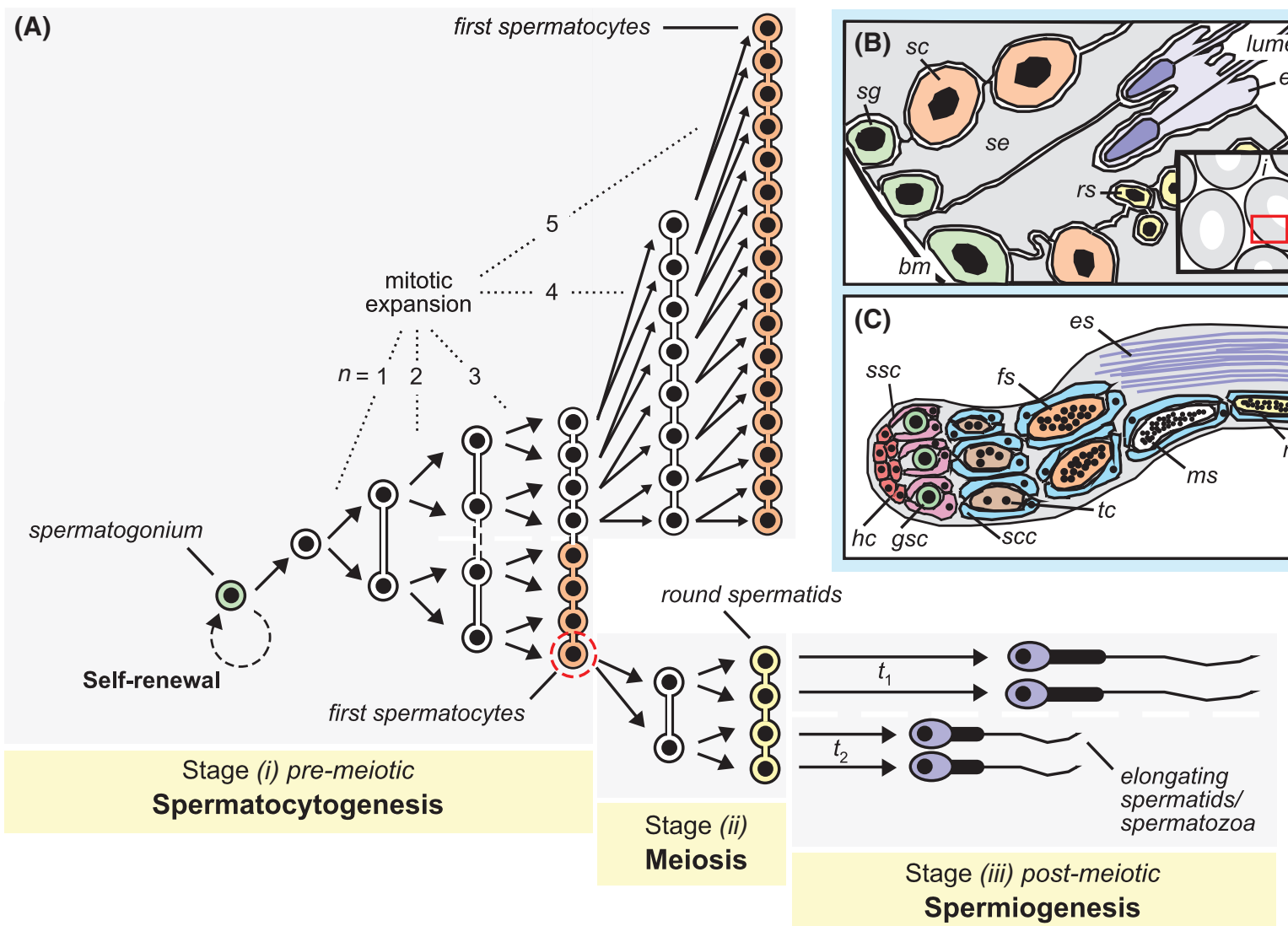

Fig. 1. The process of spermatogenesis. (A) The three main stages of spermatogenesis: (i) spermatocytogenesis, (ii) meiosis, and (iii) spermiogenesis, including the illustration of two major sources of variation. First, the number of mitotic divisions during spermatocytogenesis, depicted here as $n=5$ rounds of mitotic expansion after the initial spermatogonial division in the (incomplete) upper half of the panel, but only $n=3$ rounds for the lower half of the panel (in both cases producing $2^{n}$ first spermatocytes). The subsequent steps of spermatogenesis are shown for a single first spermatocyte (circled in red). Note that the cells in the same clone of first spermatocytes usually stay connected by cytoplasmic bridges until the end of spermiogenesis. Second, the duration of spermiogenesis, represented by $t_{1}$ for the (long) upper two sperm and $t_{2}$ for the (short) lower two sperm (see detailed description in Section I.2). (B) A generalised depiction of spermatogenesis in mammals: bm, basal membrane; es, elongating spermatid; rs, round spermatid; sc, spermatocyte; se, Sertoli cell; sg, spermatogonium. The inset shows the tubular arrangement in a testis cross section, with interstitial tissue (i) between adjacent tubules, part of which is drawn in detail in the main panel. Redrawn from Roosen-Runge (1977). (C) A generalized depiction of spermatogenesis in the testicular tip of drosophilid flies: es, elongating spermatids; fs, first spermatocytes; gsc, germline stem cells; hc, hub cells; ms, meiotic spermatocytes; rs, round spermatids; scc, somatic cyst cells; ssc, somatic stem cells; tc, transit cells. Redrawn from Schärer et al. (2008) and http://flyted.zoo.ox.ac.uk.

\section{(3) Testicular architecture}

A complementary approach to considering testicular function is to focus not on its histology, but instead on the logical organisation of its cells and their hierarchical relationships. Recent evolutionary theory investigates how the function and integrity of a renewing tissue is affected by variation in the logical organisation of its cell types and their division patterns, termed tissue architecture (Frank, Iwasa \& Nowak, 2003; Frank \& Nowak, 2004; Frank, 2007). Given that the testis can also be considered a renewing tissue, these theoretical insights are highly relevant to the testis (Schärer, Da Lage \& Joly, 2008), thus requiring consideration of how selection on sperm demand may be reflected in the testicular architecture. Briefly, the production of $k$ differentiated cells requires $k-1$ cell divisions (if one assumes that no cell death occurs) and can be achieved by very different cellular topologies, including variation in: $(i)$ the number of stem cells (spermatogonia) established when the testis is initially formed; (ii) the rate at which each of these stem cells divides asymmetrically (spermatogonial divisions) to produce daughter cells that become (differentiating) transit cells; and (iii) the number of symmetric (binary) divisions exhibited by these transit cells (number of rounds of mitoses during mitotic expansion before the two meiotic divisions). Some possible topologies are depicted in Fig. 2 (redrawn from Schärer et al., 2008), all of which lead to one stem cell (spermatogonium, green) and eight differentiated cells (first spermatocytes, orange). These examples show that the testis could in theory respond to selection on altered demand by adjusting its architecture in several different ways. However, given the 


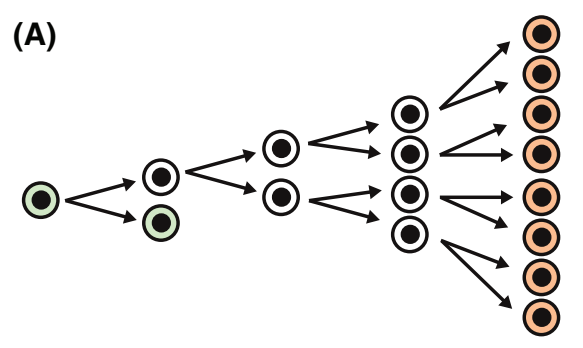

(C)
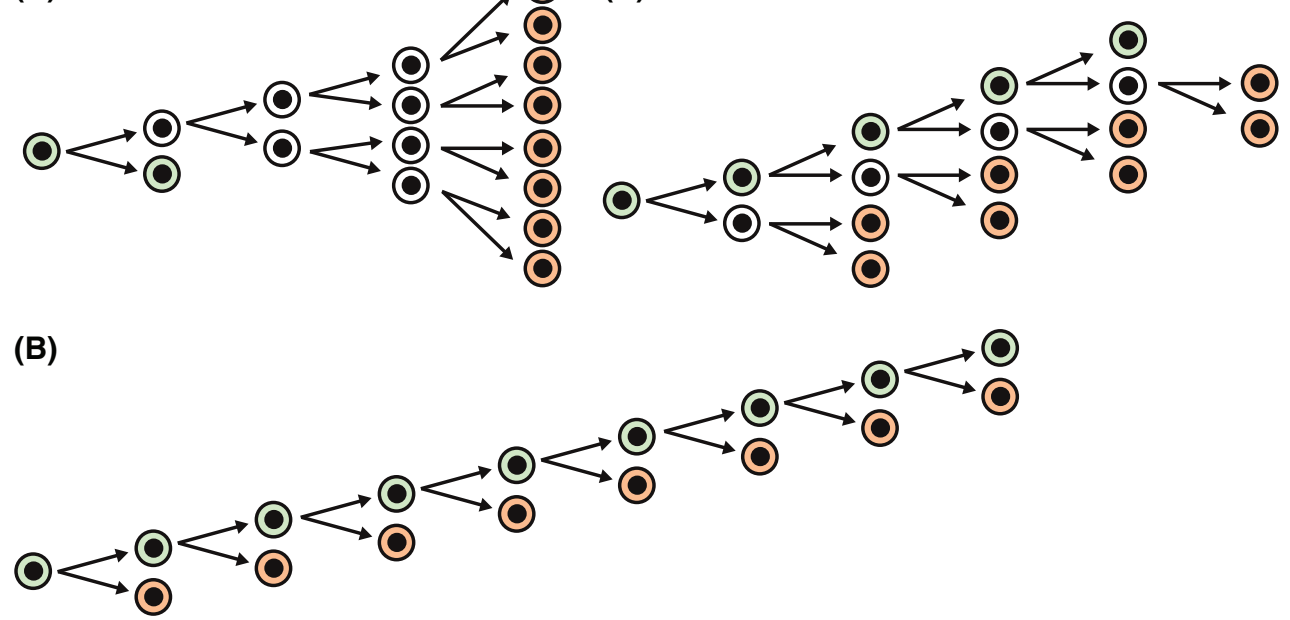

Fig. 2. Spermatogenesis and testicular architecture. Three possible branching topologies that all involve a single spermatogonium (green) producing one daughter stem cell (green) and eight spermatocytes (orange). In (A) this is achieved by just one (asymmetric) stem cell division with several rounds of (binary) transit cell divisions (white); in (B) by the stem cell dividing asymmetrically eight times, and no transit cell divisions; and in $(\mathrm{C})$ by an intermediate topology (see also Section I.3). Note that whilst useful for thinking about the range of possibilities, these different topologies may themselves be an over-simplification of the different patterns of stem and transit cell division actually observed within the testis. Recent experimental evidence argues against a purely asymmetric division model of stem cell self-renewal and differentiation, instead favouring a stochastic division model (see Klein et al., 2010; Yoshida, 2012). Such stochastic topologies have yet to be modelled in the context of the evolution of tissue architecture.

risk of proliferation-induced mutations - an accumulation of which can affect tissue function and even lead to malignant cell lines - theory suggests that cell divisions in an epithelium should preferably occur in the cell that has so far divided least often, i.e. cells at the tip of the branches (step iii above). The need for differentiated cells in renewing tissues, however, limits the length that these branches can attain: in the testis, in order to reproduce, differentiating transit cells must eventually become differentiated sperm cells. It has been argued that such constraints may actually explain the need for long-lived stem cells in renewing tissues, allowing a shift in the divisions away from step iii to steps $i$ and $i i$ (Frank et al., 2003). The establishment of basal stem cells would then in turn have led to selection for adaptations in these stem cells that reduce the risk of acquiring mutations (Cairns, 2006; Frank, 2007; De Rooij, 2011). As we outline in this review, there is dramatic variation in testicular architecture, both within and between species, and, again, some of this variation is likely due to post-mating sexual selection.

\section{(4) Scope}

In the following we first focus on features of testicular function that are most immediately relevant to two major targets of post-mating sexual selection, namely the number and morphology of sperm produced, both over ecological and evolutionary timescales. We then broaden our focus to consider how testicular function is shaped by variation in sperm demand, first by considering different temporal sperm production schedules over an individual's lifetime, and then by exploring the effects of rapidly fluctuating selection pressures on sperm number and morphology over evolutionary time. We point out how an appreciation of the evolutionary ecology of testicular function links to wider questions in biology, such as testicular cancer, intragenomic conflict and male-biased mutation, and conclude by suggesting additional approaches that should now be applied to study testicular function. Throughout the review, we highlight recent empirical advances and develop a conceptual framework for thinking about testicular function in an evolutionary context. Applying this framework leads to many often novel and empirically untested predictions (summarised in Table 2). We limit our attention to the function of the testis; an ultimate accounting for how post-mating sexual selection shapes male reproductive function will also need to incorporate the effects of selection on related male traits such as genitalia and seminal fluid (Hosken \& Stockley, 2004; Poiani, 2006; Simmons \& Fitzpatrick, 2012; Perry, Sirot \& Wigby, 2013).

\section{HOW DOES THE TESTIS MAXIMISE SPERM OUTPUT?}

\section{(1) The amount of spermatogenic tissue}

The testis contains both spermatogenic and nonspermatogenic tissue, the relative proportions of which can vary widely among species. For example, in one survey of 12 mammal species the percentage of spermatogenic tissue ranged from $32.7 \%$ by volume in the woodchuck (Marmota monax) to $92.7 \%$ in the degu (Octodon sp.) (Russell et al., 1990). 
Table 2. Summary of predictions about the evolution of testicular function derived from or linked to the framework discussed in this review (SG, sperm competition), and examples of studies that support these predictions (NA, not available to our knowledge)

$\overline{\text { Prediction from section } \quad \text { Current evidence }}$

I.3 Testicular architecture

(1) SC selects for more testicular stem cells per unit size of testis

(2) SC selects for higher rates of stem cell division (see also prediction 9)

(3) SC selects for more mitotic expansion steps

II. 1 The amount of spermatogenic tissue

(4) The amount of spermatogenic versus steroidogenic tissue varies with the relative strength of post- versus pre-mating sexual selection

(5) Higher competition over social dominance leads to higher proportion of steroidogenic tissue (may result from prediction 4)

(6) SC leads to higher proportion of spermatogenic tissue (may result from prediction 4)

II.2 The speed of spermatogenesis

(7) SC leads to faster spermatogenesis [and a shorter seminiferous epithelium cycle length (SECL)] (but see predictions 3 and 9)

II.3 Sperm production plasticity

(8) Phenotypic plasticity in sperm production rate involves not just changes in testis size, but also changes in testicular efficiency

III.1 Sperm morphology and spermatogenesis

(9) SC often leads to longer/larger sperm

(10) Longer sperm require larger testes and wider seminiferous tubules

(11) Longer/larger sperm require a longer spermiogenesis and longer SECL

(12) Longer sperm are associated with fewer mitotic expansion steps

(13) More complex sperm require a longer spermiogenesis

III.2 Variation and plasticity in sperm morphology within species

(14) SC leads to less between- and within-individual variation in sperm size (needs to consider confounding due to prediction 9)

(15) Phenotypic plasticity in sperm morphology is reflected in testicular histology and testicular architecture

IV.1 Seasonality and fluctuating sperm demand

(16) Highly seasonal breeders have few stem cells per unit testis size, more mitotic expansion steps, few concurrent spermatogenic stages, and produce many sperm per unit testis size

(17) Mature testes in semelparous breeders show proliferation-induced damage and widespread loss of stem cell function

(18) Continuous breeders have more well-protected stem cells, fewer mitotic expansion steps, all concurrent spermatogenesis stages, and thus produce fewer sperm per unit testis size

IV.2 Temporal separation of sperm production and sperm use

(19) Temporal separation of sperm production and sperm use may weaken some of the predictions outlined in Section IV.1

(20) Temporal separation of sperm production and sperm use favours testicular adaptations to protect sperm from oxidative stress, ageing and degradation

(21) Temporal separation of sperm production and sperm use results from high demands on pre-mating or other investment during the breeding season

IV.3 Sperm heteromorphism

(22) Sperm heteromorphism can favour specific sperm production schedules, reflected in testicular histology and testicular architecture

V.1 Proliferation-induced mutations

(23) Testicular architecture favours mutations in transit cells over stem cells, as the former 'wash' out, while the latter do not

(24) SC selects for more (mutation-prone) mitotic expansion steps

(25) In the short term SC favours ways to increase sperm-production rate that may in the long term cause problems

V.2 Intragenomic conflict

(26) Low SC increases the scope for intragenomic conflict

(27) Shifts in testicular architecture and sperm morphology, and the timing of spermatogenesis, may affect the efficacy of mechanisms controlling transposable element activity, leading to mutations
NA

Correlated to testis size (Schärer et al., 2004); per unit size of testis, NA

Possibly Schärer et al. (2008)

Moreira et al. (1997b)

Moreira et al. (1997a)

Several studies, see Section II.1 for details

Peirce \& Breed (2001), Parapanov et al. (2008) and Ramm \& Stockley (2010)

Schärer \& Vizoso (2007) and Ramm \& Stockley (2009)

See Pitnick et al. (2009) and Montgomerie \& Fitzpatrick (2009)

Pitnick (1996) and Lüpold et al. (2009b)

Pitnick et al. (1995b), LaMunyon \& Ward (1998) and Ramm \& Stockley (2010)

Schärer et al. (2008)

NA

Several studies, see Section III.2 for details

NA

NA

NA

NA

NA

Several studies, see Section IV.2 for details

NA

NA

NA (see Frank et al., 2003 for details)

Possibly Schärer et al. (2008)

NA

Price et al. (2008)

NA 
This means that differences in testis size alone need not necessarily reflect differences in sperm production parameters, which are likely the true target of selection under sperm competition, and similar arguments may well hold for other animal groups. In fact, because much of the non-spermatogenic tissue in the mammalian testis is involved in androgen production (i.e. the Leydig cells of the interstitial tissue), increases in testis mass may sometimes even evolve in response to pre-mating sexual selection on androgen production in the context of aggressive or territorial behaviour. This has been shown for capybara (Hydrochoerus hydrochoeris), where there are positive correlations between residual testis mass and residual size of two androgen-dependent scent glands, but no correlation between residual testis size and the amount of spermatogenic tissue (e.g. Moreira, MacDonald \& Clarke, 1997b), and where testes of adult males on average contain a striking $72 \%$ of interstitial tissue (Moreira, Clarke \& MacDonald, 1997a). Moreover, very high proportions of interstitial tissue also occur in other mammal species, such as wild boar (Sus scrofa) and zebra (Equus burchelli) (Fawcett, Neaves \& Flores, 1973). Whilst testicular functions other than sperm production are not the main focus of our review, we want to reiterate that they exist (see review in Stocco \& McPhaul, 2006), and that this is bound to complicate the relationship between testis size and sperm output.

The first studies systematically to investigate the relationship between mating system and male investment in sperm production, conducted in primates, recognised the difficulty of equating testis size with sperm production. Thus not only did they uncover a strong link between the degree of multiple mating by females and relative testis size (Short, 1979; Harcourt et al., 1981), but importantly they also established that across six different primate genera, the testis indeed contains both more, and a higher proportion of, spermatogenic tissue in lineages subject to higher levels of sperm competition (Harcourt et al., 1981; but see Møller, 1989).

Despite these early insights, however, the great majority of subsequent studies in the sperm competition literature have simply assumed that bigger testes have a higher overall spermatogenic activity (discussed in Schärer, Ladurner \& Rieger, 2004), and gone on to establish links between relative testis size and related traits. More recently, there has been a revival of interest in considering the amount of spermatogenic tissue the testis contains. In New World blackbirds (Icteridae) (Lüpold et al., 2009b), the Australian passerine family Maluridae (Rowe \& Pruett-Jones, 2011), and in four closely related mouse species (Montoto et al., 2012), those species subject to high levels of sperm competition have been found to exhibit testes containing a higher proportion of spermatogenic tissue. This demonstrates that in order to attain a higher spermatogenic activity, sperm competition can select not only for a larger, but also for a more efficient testis (see also Wistuba et al., 2003; Luetjens, Weinbauer \& Wistuba, 2005; and Table 1 for brief discussion of the various definitions of 'spermatogenic efficiency').

\section{(2) The speed of spermatogenesis}

The speed of spermatogenesis is known to vary widely across and even within species (Amann, 1970; RoosenRunge, 1977). The methods that are used to measure it, such as BrdU labelling (see Table 1) and other cell proliferation assays, could readily be applied to a range of taxa of evolutionary interest (Schärer et al., 2004, 2007). Recent studies in mammals provide correlative evidence for a role of sperm competition in generating interspecific diversity in spermatogenesis kinetics. Peirce \& Breed (2001) conducted a detailed comparison of two Australian rodents differing in sperm competition level. They measured the seminiferous epithelium cycle length (SECL), a measure of the speed with which the spermatogenic tissue in the testis is turning over, which in turn determines the total duration of spermatogenesis (for details see 'spermatogenesis kinetics' in Table 1). Peirce \& Breed (2001) found that SECL is significantly shorter in the promiscuous plains rat (Pseudomys australis) than in the hopping mouse (Notomys alexis), a species with extremely small testes and low or absent sperm competition (Breed \& Adams, 1992). Similarly, SECL among six shrew species is negatively correlated with relative testis size (Parapanov et al., 2008). A recent, phylogenetically controlled comparative analysis across 33 mammalian species supports the hypothesis that sperm competition drives faster rates of spermatogenesis: after controlling for differences in sperm size (see Section III.1), there is a negative correlation between inferred levels of sperm competition and SECL (Ramm \& Stockley, 2010).

\section{(3) Sperm production plasticity}

Many animals can adjust sperm production according to environmental cues indicative of the expected level of sperm competition. Among invertebrates, various sperm production traits respond to factors including larval density or social group composition (e.g., Gage, 1995; Oppliger, Hosken \& Ribi, 1998; Stockley \& Seal, 2001; Tan, Govedich \& Burd, 2004; Bjork, Dallai \& Pitnick, 2007). For example, in the flatworm Macrostomum lignano worms raised in larger social groups have larger testes (Schärer \& Ladurner, 2003; Brauer, Schärer \& Michiels, 2007), a heightened testicular cell proliferation activity (Schärer et al., 2004), and produce more sperm (Schärer \& Vizoso, 2007). Furthermore, given that sperm production in large social groups is higher per unit testis size, other sperm production parameters, such as the speed of spermatogenesis or the size of the produced sperm (but see Janicke \& Schärer, 2010), may also vary in response to social conditions (Schärer \& Vizoso, 2007).

Vertebrate studies also indicate plastic responses to sperm competition. Testis size variation is associated with relevant temporal or geographic variation in birds and mammals (Ribble \& Millar, 1992; Brown \& Brown, 2003; Long \& Montgomerie, 2006), and experimental evidence of phenotypic plasticity in sperm production in response to social cues of sperm competition risk has now been found in house mice (Mus musculus domesticus) (Ramm \& Stockley, 
2009). Again, this result was not entirely attributable to changes in testis size, demonstrating the need to examine additional aspects of testicular function.

\section{WHAT KIND OF SPERM IS REQUIRED?}

\section{(1) Sperm morphology and spermatogenesis}

Sperm display extraordinary morphological diversity (Pitnick, Hosken \& Birkhead, 2009), much of which may be due to post-mating sexual selection and sexual conflict (e.g. Miller \& Pitnick, 2002; Fitzpatrick et al., 2009; Schärer et al., 2011; Higginson et al., 2012). The point we wish to emphasise here is that all sperm of course originate from undifferentiated spermatogonial stem cells, so sperm with different morphologies may place vastly different demands on the machinery of spermatogenesis.

The most compelling link between sperm morphology and testicular function comes from Drosophila. Many species of this genus produce giant sperm, reaching an extreme in the $58 \mathrm{~mm}$ long sperm of D. bifurca (Pitnick, Spicer \& Markow, 1995b). The cost of producing such long sperm is substantial and morphologically well reflected (Pitnick \& Markow, 1994; Pitnick, Markow \& Spicer, 1995a), necessitating both longer testes (Pitnick, 1996) and specialised sperm-processing and storage structures (Joly, Luck \& Dejonghe, 2008). Moreover, the spermatid elongation phase for the $c a .2 \mathrm{~mm}$ sperm of $D$. melanogaster takes less than 2 days, whereas it takes 12 days for the $23 \mathrm{~mm}$ long sperm of $D$. hydei (see Pitnick, 1996). Sperm length also strongly correlates with testicular architecture, in that species exhibiting longer sperm have fewer rounds of mitosis and consequently fewer first spermatocytes; so far fewer sperm result from each spermatogonial division compared to species with shorter sperm (Schärer et al., 2008).

Even for species groups with less extreme variation in sperm morphology, some of the same principles are likely to hold. For example, the importance of sperm morphology for testis morphology has recently been investigated in birds, with Lüpold et al. (2009b) finding that both relative testis size and sperm length covary positively with seminiferous tubule width in New World blackbirds (Icteridae). This is apparently a direct effect of increasing sperm size causing an increased height of the seminiferous epithelium (Lüpold et al., 2009b), a conclusion supported by the absence of a positive effect of relative testis size on seminiferous tubule width in Old World Warblers (Sylvidae), a group in which sperm competition apparently selects for shorter rather than longer sperm (Immler \& Birkhead, 2007).

Sperm morphology also affects the speed of spermatogenesis in other taxa, for example among Caenorhabditis elegans strains differing in sperm size (LaMunyon \& Ward, 1998). In mammals, a recent interspecific comparative analysis suggests positive, correlated evolution of sperm length with the seminiferous epithelium cycle length, SECL (Ramm \& Stockley, 2010). Such links between sperm size and the speed of spermatogenesis suggest one mechanism through which an evolutionary trade-off between sperm size and number - a core assumption of many sperm competition models - may be mediated (Pitnick, 1996; Ramm \& Stockley, 2010). Moreover, given the drastic variation in sperm design among species (Pitnick et al., 2009; Schärer et al., 2011), we can similarly expect that morphologically more complex sperm will require a longer spermatogenesis, but we are unaware of studies that specifically investigate this. It may also be interesting to turn this question around, and ask how constraints on testis morphology might limit or shape the response of sperm morphology to post-mating sexual selection (Gomendio, Tourmente \& Roldan, 2011).

\section{(2) Variation and plasticity in sperm morphology within species}

In intraspecific studies a recurring pattern is for sperm morphometry to differ substantially among individuals but relatively little within individuals, both in species with separate sexes (Ward, 1998; Morrow \& Gage, 2001) and in hermaphrodites (Minoretti \& Baur, 2006; Janicke \& Schärer, 2010). To elucidate the origin of these patterns comparative analyses in different bird groups have suggested that betweenindividual variation in sperm size is most pronounced in species subject to low levels of sperm competition, probably due to relaxed selection on an optimal sperm morphometry and so too presumably on other aspects of spermatogenesis (Birkhead et al., 2005; Calhim, Immler \& Birkhead, 2007; Kleven et al., 2008; Lüpold, Linz \& Birkhead, 2009a). Moreover, there may also be a role for post-mating sexual selection in explaining patterns of within-individual variation in sperm morphometry, since bird species subject to high levels of sperm competition are also those that show the lowest levels of standardised within-individual variation in sperm size (Immler, Calhim \& Birkhead, 2008), which has led to the suggestion that sperm competition may select for enhanced quality control during spermatogenesis (see also Lüpold et al., 2011).

However, caution may be needed in interpreting these results about between- and within-male variation in sperm size, since it is not always clear what the null hypothesis should be. When considering how sperm competition impacts on sperm variability, one needs to take into account the fact that the level of sperm competition and sperm length often co-vary (Montgomerie \& Fitzpatrick, 2009; Pitnick et al., 2009). Thus one needs to ask how variation in sperm length is expected to change with sperm length. Two contrasting scenarios are that $(i)$ variation stays constant with changes in sperm length (i.e. the testicular machinery has a limited but constant accuracy to regulate the rate and/or timing of material deposition involved in sperm elongation), or conversely that (ii) the variation scales linearly with sperm length (i.e. the accuracy of the testicular machinery is a linear function of sperm size). Note that intermediate scenarios are of course also possible. In the former scenario, which we consider somewhat more likely given that longer sperm take longer to make, the coefficient of variation in sperm length would necessarily become smaller in larger sperm, but such an effect 


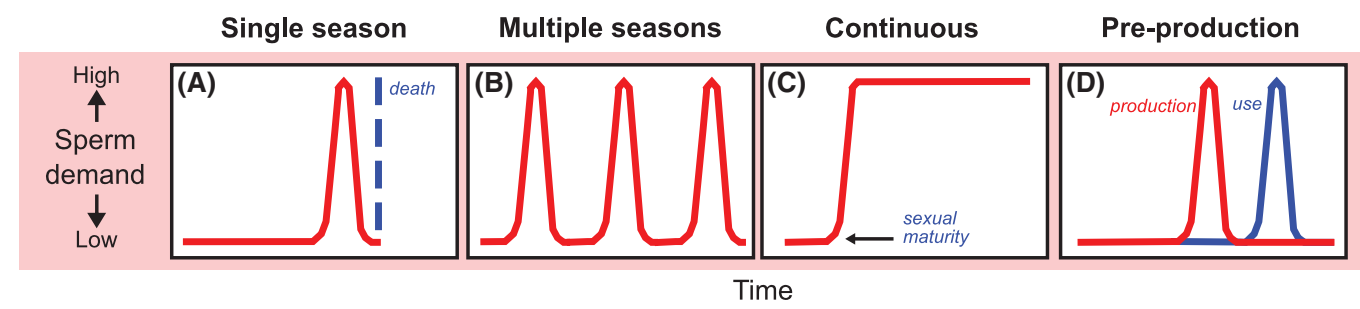

Fig. 3. Different patterns of sperm demand over time and consequent sperm production schedules. The figure illustrates four generic sperm demand scenarios, (A) a species with a single mating season (semelparity); (B) a species with multiple mating seasons (seasonal iteroparity), interspersed with periods of low sperm demand; $(\mathrm{C})$ a species that breeds continuously upon attaining sexual maturity; and (D) a species in which there is a temporal separation between sperm production (red) and sperm use (blue). The evolutionary consequences of these different production schedules are considered in detail in Section IV.

would not necessarily represent selection for an increased accuracy. In the latter scenario, which seems biologically less likely, the null hypothesis would be that the coefficient of variation does not change with sperm size, and this is what the outlined studies have actually tested. Moreover, the extensive evidence for large between-individual and small within-individual differences (see previous paragraph) actually suggests that consistently making sperm of a specific length is not so hard (and that stabilising selection on a particular sperm length is not so strong). Unfortunately, how these differences in sperm length and variation originate and how they are reflected in testis morphology or architecture remains essentially unknown. We hope that the patterns of variation in sperm size will be revisited in the light of these additional considerations.

In addition to the sperm production plasticity described in Section II.3, a number of recent studies indicate that sperm morphometry itself can be a phenotypically plastic trait (e.g. Crean \& Marshall, 2008; Morrow, Leijon \& Meerupati, 2008; Vermeulen et al., 2009; Immler et al., 2010; but see Janicke \& Schärer, 2010). This implies that males may sometimes adjust the machinery of spermatogenesis to prevailing environmental conditions, but the precise changes in testicular function required to produce different sperm morphologies, as well as in many cases the adaptive value of this variation (but see Crean \& Marshall, 2008), remain to be investigated.

\section{WHEN ARE SPERM NEEDED?}

The evolution of testicular function is also likely to be affected by how life history and ecological parameters of a given species affect the temporal requirements for sperm production.

\section{(1) Seasonality and fluctuating sperm demand}

An organism with a single short mating season, or a single mating event (Fig. 3A), needs all its sperm to be mature at the same time, and spermatogenesis may therefore occur in synchrony within the entire testis. Spermatogonial divisions would likely occur well before the mating event, followed by many rounds of mitosis (since the clear endpoint does not put strong constraints on the branch length of testicular architecture) and then meiosis and spermiogenesis may occur relatively close to the (expected) time of mating. Such a testis would, at any specific time point, lack many of the stages that are normally present simultaneously. It may thus have a high sperm production for its final size (i.e. a high spermatogenic efficiency), change drastically in size over the season, and have relatively few spermatogonia (most of the amplification happens at the transit cell stage). An interesting taxonomic group in which to explore this could be fishes, where such data are available for a range of species and where there appears to be substantial variation in branch lengths (e.g. Fishelson, 2003), or broadcast-spawning marine invertebrates with mass-spawning events.

Moreover, we can expect a radically different testicular organisation when such an organism is semelparous versus iteroparous. In the former case (Fig. 3A), protection from malignant cell lines is of little concern for the lifetime reproductive success of the individual (although malignant cells may of course affect spermatogenic efficiency) and we would therefore expect to find obvious signs of proliferationinduced damage and widespread loss of stem cell function once the testis has matured. In the latter case (Fig. 3B), the survival of the individual to the next mating season is crucial for its lifetime reproductive success; we would thus expect a low incidence of malignant cell lines, and the presence of at least some well-protected stem cells that retain their function after the seasonal testis maturation, which are then later recruited to reinitiate spermatogenesis for the next mating season.

Next we can contrast the above scenarios with a species that needs to produce a fairly constant supply of sperm once it reaches maturity (Fig. 3C). Here, the constant demands for having differentiated sperm would likely put a constraint on the lengths of the transit cell branches of the testicular architecture (i.e. a reduced mitotic expansion), leading to fewer spermatocytes per spermatogonial division, and thus requiring more spermatogonia or more spermatogonial divisions (i.e. a high stem cell activity) to maintain a high sperm production rate. Shifting the proliferation load onto the spermatogonial stem cells may require efficient mechanisms to control the appearance of malignant cell 
lines (Frank et al., 2003; Cairns, 2006). Given the highly variable and rapidly changing selection regimes that sperm competition places on sperm production, we can expect that proliferation-induced damage is an important aspect of testicular function (see Section V.1).

\section{(2) Temporal separation of sperm production and sperm use}

If the ability to produce sperm is constrained during the mating season, for example due to severe energy demand for brood care or territorial defence, then it may be advantageous to shift production to well ahead of time, and to retain already matured sperm in storage until the mating season (Fig. 3D). This in turn may require special adaptations to protect sperm from oxidative stress (Almbro, Dowling \& Simmons, 2011), and it has been suggested that testicular melanisation (i.e. the incorporation of pigments into the tissues of the testis) might have this function (Zieri, Taboga \& De Oliveira, 2007; Galvan, Møller \& Erritzøe, 2011) (although this has also been suggested to be linked to thermoregulation of spermatogenesis in a lizard that shows a striking pattern of unilateral testicular melanisation; Guillette, Weigel \& Flater, 1983). A case in point is the three-spined stickleback (Gasterosteus aculeatus), where sperm are made several months before the mating season and stored in the testis (Borg, 1982; Zbinden, 2001), where the testis is strongly melanised (Mehlis et al., 2012), and where brood care and territorial defence are very energy demanding (Smith \& Wootton, 2005). If this scenario is correct, testicular melanisation might be correlated with the amount of pre-mating sexual investment. Other interesting systems worthy of investigation in the context of extended sperm storage include snakes such as the adder Vipera berus, in which sperm production occurs during an immobile phase prior to the breeding season (Olsson, Madsen \& Shine, 1997), and bats, some of which store sperm for prolonged periods in both the male and female reproductive tract (Racey, 1979).

\section{(3) Sperm heteromorphism}

A final interesting aspect of sperm production schedules concerns so-called sperm heteromorphic species (e.g. some insects, gastropods, spiders, centipedes and fish), where the same testis produces more than one type of sperm (Hodgson, 1997; Swallow \& Wilkinson, 2002; Hayakawa, 2007). In the case of a fertilising and a non-fertilising (e.g. anucleate) sperm morph, one might predict that the risk of accumulating mutations in the testicular stem cell population would favour a 'fertilising sperm first' production schedule, whilst the testis is in optimal functional condition. Alternatively, if such sperm would then need to remain in storage for a long period prior to use, negative effects of sperm senescence might predominate (Reinhardt, 2007; Pizzari et al., 2008), favouring the production of 'non-fertilising sperm first' production schedules. The testis of lepidopteran males (which often have a very short lifespan after emergence as adults) produce first eupyrene (fertilising) and then apyrene (nonfertilising) sperm (Friedländer, 1997). By contrast, eupyrene and apyrene sperm are produced concurrently in gastropods (Hodgson, 1997) and production of multiple fertilisationcompetent sperm morphs also occurs concurrently (although separated spatially) in Diptera and Hemiptera (Swallow \& Wilkinson, 2002).

\section{WHAT ARE THE EFFEGTS OF VARIABLE SELECTION?}

The testis is special in that it is arguably exposed to some of the most variable and fluctuating selection pressures among all organ systems, as the demands for the total amount of sperm produced (and their specific morphology) often change rapidly with shifts in the mating system and resulting postmating sexual selection (e.g. Harcourt et al., 1981; Parker et al., 1997; Schärer et al., 2011; Higginson et al., 2012). These strong and fluctuating selection pressures of postmating sexual selection may be relevant to explaining why the testis appears to be a common site of expression for novel genes (Nurminsky et al., 1998; Loppin et al., 2005; Levine et al., 2006; Heinen et al., 2009). For example, one hypothesis suggests that the testis is a common source of novel genes because of the unusually 'permissive' environment provided for the transcription of new genes during spermatogenesis (the 'out of the testis' hypothesis: Kaessmann, 2010), which may also help explain why there are so many more genes with testis- compared to ovary-specific expression (Reinke et al., 2000; Parisi et al., 2004; Chintapalli, Wang \& Dow, 2007; Haerty et al., 2007; R. Arbore, K. Sekii, C. Beisel, E. Berezikov \& L. Schärer, in preparation). In the following we discuss how the strong and fluctuating selection pressures make it difficult for the testis to evolve optimal solutions to deal with two specific problems, namely proliferationinduced mutations and intragenomic conflict, which may help to explain why the testis is so 'permissive'.

\section{(1) Proliferation-induced mutations}

The testis often has a high cell proliferation rate (both in absolute terms and compared to the ovary) leading to a considerable risk of proliferation-induced mutations during spermatogenesis. This risk may nevertheless have to be tolerated, owing to the need to achieve high rates of sperm production under sperm competition (Blumenstiel, 2007), and it has been argued that this is an important source of male-biased mutation (Bartosch-Härlid et al., 2003; Ellegren, 2007). The limited data available testing whether life-history parameters, such as rates of extra-pair paternity or relative investment in sperm production, predict the degree of male mutation bias have so far provided mixed results. The largest scale study to date found no link between the degree of male mutation bias and male investment in sperm production (measured as the testis-by-body mass ratio: Wilson Sayres et al., 2011 ; see also Møller \& Cuervo, 2003), whereas studies 
focused on more closely related species groups have tended to support a potential link (Bartosch-Härlid et al., 2003 in birds; Presgraves \& Yi, 2009 in great apes). Clearly many additional factors (e.g. generation time) could affect male mutation bias estimates, making comparisons across taxa far from straightforward, and currently no firm conclusions can be drawn (Wilson, Sayres \& Makova, 2011). Moreover, recent evidence also indicates that in some cases the testis is not simply a passive vessel in which de novo mutations arise and are transmitted. Instead, some mutations may actually be actively selected at the level of the spermatogonia, as they provide a proliferative advantage to the spermatogonia in which they arise. A strong selective advantage of that kind would likely lead to testicular cancer, but if the advantage is sufficiently weak it may lead to the spread of such a mutation, unless there are negative pleiotropic effects, which is the context in which the currently known genes of this kind have actually been identified (e.g. Qin et al., 2007; Arnheim \& Calabrese, 2009).

As we have argued above, proliferation-induced mutation risk may be partially controlled by having an appropriate testicular architecture. One important insight from the models is that mutation rates should be lower in stem cells (spermatogonia) than in transit cells (spermatocytes and spermatids), because transit cell mutations 'wash out' of the system, while mutations in stem cells may lead to all subsequent progeny of that cell carrying the mutation in question (Frank et al., 2003; Nowak, Michor \& Iwasa, 2003). We could therefore expect that keeping the stem cells free of mutations would usually be more important than preventing mutations in some of the sperm, even if these are then inherited to some offspring.

Given this scenario it is therefore crucial to understand whether the testis reacts to an increased sperm demand by producing more (mutation-protected) stem cell divisions, or by increasing the number of (mutation-prone) spermatocyte divisions and thus increasing the branch lengths of the tissue architecture. If it occurs via the latter mechanism, which seems at least sometimes to be the case given the extensive variation in transit cell branch length in the Drosophilidae (Schärer et al., 2008), this preference for mutations that 'wash out' could contribute substantially to the male mutation rate (as limited haploid gene expression may in fact mask these mutations from selection, see also Section V.2). Moreover, periods of increased demand for sperm production may lead to the spread of alleles that lead to an increased (testicular) proliferation rate and cellular growth, even if these have harmful pleiotropic effects on cell proliferation in the context of cancer (Crespi \& Summers, 2005; Kleene, 2005), which may also help to explain some unusual gene expression patterns in spermatogenesis (Kleene, 2005; White-Cooper et al., 2009; White-Cooper \& Bausek, 2010).

\section{(2) Intragenomic conflict}

Spermatogenesis can lead to intragenomic conflict between the diploid father and its haploid sperm (Haig \& Bergstrom, 1995; Joseph \& Kirkpatrick, 2004; Immler, 2008; Higginson
\& Pitnick, 2011). While the father is equally related to all of his sperm, in diploid species sperm on average share only half of their alleles with any given sibling sperm. An allele that permits a sperm to outcompete sibling sperm may therefore have a transmission advantage, as evidenced by some well-known meiotic drive systems (e.g. the $t$-haplotype in mice and Segregation Distorter in Drosophila: Joseph \& Kirkpatrick, 2004; Lewis, Price \& Wedell, 2008). Two traits of spermatogenesis have been suggested to limit the time window for such genomic conflict to emerge, namely postmeiotic condensation and packaging of nuclear material (reducing the possibility for haploid gene expression), and the maintenance of cytoplasmic bridges connecting the developing spermatids (leading to sharing of expression products, thus making these haploid cells essentially phenotypically diploid: Erickson, 1973; Haig \& Bergstrom, 1995).

Interestingly, there is now accumulating evidence for at least some haploid expression (Joseph \& Kirkpatrick, 2004; Barreau et al., 2008; Vibranovski et al., 2010), suggesting that these control mechanisms may not be perfect. As has previously been pointed out (Haig \& Bergstrom, 1995), the risk for meiotic drive alleles to invade is likely to be higher under conditions of low sperm competition (i.e. when interactions generally occur between related sperm). One reason for this is that driving alleles are often associated with reduced fertility (Joseph \& Kirkpatrick, 2004), which leads to selection against them under conditions of high sperm competition (actually a proposed reason for multiple mating in females: Price et al., 2008; Manser et al., 2011) and another is that the presence or absence of sperm from another male strongly affects how likely related sperm are to have cooperative versus competitive interactions (Haig \& Bergstrom, 1995; Pizzari \& Foster, 2008). Thus low sperm competition following an evolutionary period of high sperm competition may be particularly likely to lead to the invasion of meiotic drive alleles, as restorer alleles may have been lost from the population. Low sperm competition may thus not only lead to relaxed selection on sperm production, but also to positive selection on dealing with more intense genomic conflict.

Variable and fluctuating selection pressure on testicular function may also affect the ability to control a second important source of intragenomic conflict linked to mutation, namely the activity of transposable elements (TEs). It is now well established that TEs tend to be primarily active during different phases of germ-line formation and spermatogenesis (and also oogenesis) (Werren, 2011; Bao \& Yan, 2012; Wedell, 2013), likely as a result of two main processes. Firstly, there is widespread reprogramming of TE-silencing epigenetic marks during the proliferation of the primordial germ cells (Werren, 2011; Bao \& Yan, 2012), which could affect the number of mutations initially seeded into spermatogonia (and mutations that occur at this stage may also be important for tissue architecture: Frank \& Nowak, 2003). Secondly, recombination and repackaging of DNA from histones to protamines during meiosis opens up the possibility for TEs that usually reside in highly condensed DNA regions to be released (Bao \& Yan, 2012). Both of these phases involve 
complex molecular mechanisms that regulate re-methylation and control of TE activity, often involving highly complex timing of gene regulation (Bao \& Yan, 2012). It seems likely that strong selection on altering sperm output (e.g. via mitotic expansion) and/or sperm morphology (e.g. via sperm elongation) may lead to shifts in the timing of these processes, potentially leading to loss of control over TE activity.

\section{OUTLOOK}

We have illustrated how post-mating sexual selection could, and indeed does, shape multiple aspects of spermatogenesis besides relative testis size. Several other approaches in evolutionary biology that we have not touched on here could also shed new light on the evolutionary ecology of testicular function. Quantitative genetics can uncover genetic constraints on the evolution of sperm and other sexually selected traits (Moore et al., 2004; Birkhead et al., 2005; Simmons \& Moore, 2009; Evans, 2010), and molecular evolutionary studies can provide revealing insights into how the genes underpinning reproductive traits evolve (Swanson \& Vacquier, 2002; Turner \& Hoekstra, 2008). For example, we have already seen that a key parameter in Drosophila spermatogenesis is the timing of the switch from mitosis to meiosis. Some of the genes implicated in this switch display an excess of nonsynonymous substitutions in specific Drosophila lineages (Civetta et al., 2006; Bauer DuMont et al., 2007) and it will be of great interest to establish whether these or additional molecular differences among species can account for divergence in testicular architecture (Schärer et al., 2008). With the increasing availability of molecular data, we can expect such attempts to link genotypic and phenotypic variation will become a major focus of sperm competition research.

A potentially powerful technique not yet brought to bear directly on the process of spermatogenesis is that of experimental evolution (Garland \& Rose, 2009). Multiple studies in insects have observed differences in testis size among males from lines evolving under differing levels of sperm competition (see Section I.1) and coevolution of sperm morphology with female reproductive tract morphology (Miller \& Pitnick, 2002), but there have been no detailed investigations with respect to the consequences of these experiments for aspects of testicular machinery beyond gross testis size. Also, given that we have identified a number of processes that may affect the proper function of the testis, we suggest that more emphasis should be placed on reporting 'odd' or 'unusual' testicular phenotypes resulting from artificial selection or experimental evolution studies that select for either higher or lower sperm production. Moreover, such phenotypes should also be reported more often in both laboratory and field studies to understand better the patterns of failure of testicular function. In concert with technological advances in genomics and transcriptomics, such approaches could be a powerful means to address the coevolution of different aspects of testicular function that determine the number and morphology of sperm produced.
Finally, we wish to acknowledge that although we have attempted a broad survey, there are undoubtedly many relevant aspects of testicular function that we have not touched upon. In part this results from space constraints, but our own background and research interests also mean that we have approached the subject very much from an evolutionary perspective and so there could be a considerable amount of highly relevant data in the reproductive biology literature of which we are currently unaware, but that could nevertheless be brought to bear on, and be informed by, the ideas we have presented here. Moreover, a further limitation is that many of those ideas have been sketched only in verbal form, and we see considerable scope for future theoretical modelling in order to test their plausibility and make clearer predictions. Our hope therefore is that this review might also act as a stimulus towards greater interaction between evolutionary, reproductive and theoretical biologists on this important topic.

\section{GONGLUSIONS}

(1) Our aim in this review has been to highlight how the traditional 'black box' view of testicular function adopted by evolutionary biologists has come to limit our progress in understanding how this organ evolves. Just as variation in gross brain size gives a valid but only partial view of the biological basis of intelligence (McDaniel, 2005; Narr et al., 2007; Luders et al., 2008), so focussing entirely on variation in gross testis size risks ignoring other potentially adaptive features of testicular function relevant to male reproductive fitness.

(2) The studies we have cited clearly demonstrate that post-mating sexual selection can be a powerful selective pressure acting on multiple aspects of testicular function, and they highlight the need to consider more explicitly the biology of spermatogenesis.

(3) There are several ways in which the testis can adjust sperm output other than by changing gross testis size, for example via increasing the proportion of spermatogenic tissue it contains, and there is now abundant evidence that these parameters can be adjusted according to the prevailing environmental conditions over both evolutionary and ecological timescales.

(4) A key determinant of testicular function will be the kind of sperm the testis has been selected to produce, and we have documented the accumulating evidence that spermatogenesis and testicular function is strongly shaped by sperm morphology.

(5) Sperm production schedules can vary substantially, reflecting the various ways in which the life history and ecological parameters of a given species affect the temporal requirements for sperm production, with important consequences for testicular function.

(6) The testis is subject to strong and fluctuating selection pressures, which again affects the evolution of testicular function, and is highly relevant to understanding phenomena 
such as proliferation-induced mutation and intragenomic conflict.

(7) In setting out these various known and hypothesised effects on testicular function, we hope to have established a framework for studying how selection acting on sperm numbers, sperm morphology and sperm production schedules all combine to affect the evolution of spermatogenesis, the most fundamental of male reproductive traits.

\section{AGKNOWLEDGEMENTS}

We thank T. Birkhead and H. Moore for organizing the excellent Biology of Spermatozoa meetings, the attendance at and spirit of which have strongly influenced this work. We also thank T. Bakker, S. Frank, D. Joly, P. Stockley, D. Vizoso, H. White-Cooper and S. Yoshida for comments and discussion that helped inform this review, D. Ebert, L. Engqvist, K. Reinhold, T. Schmoll, P. Stockley, D. Vizoso, M. Jennions and two anonymous reviewers for their comments on the manuscript, and the Swiss National Science Foundation (grants 31003A-127503 and 31003A-143732 to L.S.) and Seventh Framework Programme of the European Union (Marie Curie Intra-European Fellowship and Career Integration Grant to S.A.R.) for financial support.

\section{REFERENGES}

Almbro, M., Dowling, D. K. \& Simmons, L. W. (2011). Effects of vitamin E and beta-carotene on sperm competitiveness. Ecology Letters 14, 891-895.

Amann, R. P. (1970). Sperm production rates. In The Testis Volume 1, (eds A. D. Johnson, W. R. Gomes and N. L. Vandemark), pp. 433-482. Academic Press, New York.

Arnheim, N. \& Calabrese, P. (2009). Understanding what determines the frequency and pattern of human germline mutations. Nature Reviews Genetics 10, 478-488.

BAO, J. \& YAN, W. (2012). Male germline control of transposable elements. Biology of Reproduction 86, 162

Barreau, C., Benson, E., Gudmannsdottir, E., Newton, F. \& White-Cooper, H. (2008). Post-meiotic transcription in Drosophila testes. Development 135, 1897-1902. Bartosch-Härlid, A., Berlin, S., Smith, N. G. C., Møller, A. P. \& Ellegren, H. (2003). Life history and the male mutation bias. Evolution 57, 2398-2406.

Bauer Dumont, V. L., Flores, H. A., Wright, M. H. \& Aquadro, C. F. (2007). Recurrent positive selection at bgcn, a key determinant of germ line differentiation, does not appear to be driven by simple coevolution with its partner protein bam. Molecular Biology and Evolution 24, 182-191.

Birkhead, T. R., Pellatt, E. J., Brekke, P., Yeates, R. \& Castillo-Juarez, H. (2005). Genetic effects on sperm design in the zebra finch. Nature 434, 383-387.

BJORK, A., Dallai, R. \& Pitnick, S. (2007). Adaptive modulation of sperm production rate in Drosophila bifurca, a species with giant sperm. Biology Letters 3, 517-519.

Blumenstiel, J. P. (2007). Sperm competition can drive a male-biased mutation rate. fournal of Theoretical Biology 249, 624-632.

BorG, B. (1982). Seasonal effects of photoperiod and temperature on spermatogenesis and male secondary sexual characters in the three-spined stickleback, Gasterosteus aculeatus L. Canadian fournal of Zoology 60,3377-3386.

Brauer, V. S., Schärer, L. \& Michiels, N. K. (2007). Phenotypically flexible sex allocation in a simultaneous hermaphrodite. Evolution 61, 216-222.

Breed, W. G. \& Adams, M. (1992). Breeding systems of Spinifex Hopping Mice (Notomys alexis) and Plains Rats (Pseudomys australis) - a test for multiple paternity within the laboratory. Australian fournal of Zoology 40, 13-20.

Brown, C. \& Brown, M. (2003). Testis size increases with colony size in cliff swallows. Behavioral Ecology 14, 569-575.

Cairns, J. (2006). Cancer and the immortal strand hypothesis. Genetics 174, $1069-1072$.
Calhim, S., Immler, S. \& Birkhead, T. R. (2007). Postcopulatory sexual selection is associated with reduced variation in sperm morphology. PLoS One 2, 413.

Cheng, C. Y. \& Mruk, D. D. (2010). The biology of spermatogenesis: the past, present and future. Philosophical Transactions of the Royal Society, B: Biological Sciences $365,1459-1463$

Chintapalli, V. R., Wang, J. \& Dow, J. A. T. (2007). Using FlyAtlas to identify better Drosophila melanogaster models of human disease. Nature Genetics 39, 715-720.

Civetta, A., Rajakumar, S. A., Brouwers, B. \& Bacik, J. P. (2006). Rapid evolution and gene-specific patterns of selection for three genes of spermatogenesis in Drosophila. Molecular Biology and Evolution 23, 655-662.

Crean, A. J. \& Marshall, D. J. (2008). Gamete plasticity in a broadcast spawning marine invertebrate. Proceedings of the National Academy of Sciences of the United States of America 105, 13508-13513.

Crespi, B. \& Summers, K. (2005). Evolutionary biology of cancer. Trends in Ecology \&ृ Evolution 20, 545-552.

Crudgington, H. S., Fellows, S., Badcock, N. S. \& Snook, R. R. (2009). Experimental manipulation of sexual selection promotes greater male mating capacity but does not alter sperm investment. Evolution 63, 926-938.

De RooiJ, D. G. (2011). Morphometric description of spermatogonial stem cells and expansion of their clonal derivatives. In Male Germline Stem Cells: Developmental and Regenerative Potential (eds K. E. Orwig and B. P. Hermann), pp. 89-105. Springer, New York.

Ellegren, H. (2007). Characteristics, causes and evolutionary consequences of male-biased mutation. Proceedings of the Royal Society B: Biological Sciences 274, 1-10.

Erickson, R. P. (1973). Haploid gene expresion versus meiotic drive: the relevance of intercellular bridges during spermatogenesis. Nature 243, 210-212.

Evans, J. P. (2010). Quantitative genetic evidence that males trade attractiveness for ejaculate quality in guppies. Proceedings of the Royal Society B: Biological Sciences 277, 3195-3201.

Fawcett, D. W., Neaves, W. B. \& Flores, M. N. (1973). Comparative observations on intertubular lymphatics and the organization of the interstitial tissue of the mammalian testis. Biology of Reproduction 9, 500-532.

Firman, R. C. \& Simmons, L. W. (2010). Experimental evolution of sperm quality via postcopulatory sexual selection in house mice. Evolution 64, 1245-1256.

Fishelson, L. (2003). Comparison of testes structure, spermatogenesis, and spermatocytogenesis in young, aging, and hybrid cichlid fish (Cichlidae, Teleostei). Fournal of Morphology 256, 285-300.

Fitzpatrick, J. L., Montgomerie, R., Desjardins, J. K., Stiver, K. A., Kolm, N. \& Balshine, S. (2009). Female promiscuity promotes the evolution of faster sperm in cichlid fishes. Proceedings of the National Academy of Sciences of the United States of America 106, 1128-1132.

Frank, S. A. (2007). Dynamics of Cancer: Incidence, Inheritance, and Evolution. Princeton University Press, Princeton.

Frank, S. A. \& NowaK, M. A. (2003). Cell biology: developmental predisposition to cancer. Nature 422, 494

Frank, S. A. \& Nowak, M. A. (2004). Problems of somatic mutation and cancer. BioEssays 26, 291-299.

Frank, S., Iwasa, Y. \& Nowak, M. (2003). Patterns of cell division and the risk of cancer. Genetics 163, 1527-1532.

Friedländer, M. (1997). Control of the eupyrene-apyrene sperm dimorphism in Lepidoptera. Fournal of Insect Physiology 43, 1085-1092.

Fuller, M. T. (1998). Genetic control of cell proliferation and differentiation in Drosophila spermatogenesis. Seminars in Cell \& Developmental Biology 9, 433-444.

GAGE, M. J. G. (1995). Continuous variation in reproductive strategy as an adaptive response to population density in the moth Plodia interpunctella. Proceedings of the Royal Society of London. Series B: Biological Sciences 261, 25-30.

Galvan, I., Møller, A. P. \& Erritzøe, J. (2011). Testicular melanization has evolved in birds with high mtDNA mutation rates. Fournal of Evolutionary Biology 24 988-998.

Garland, T. \& Rose, M. R. (eds) (2009). Experimental Evolution. University of California Press, Berkeley.

Gomendio, M., Tourmente, M. \& Roldan, E. R. S. (2011). Why mammalian lineages respond differently to sexual selection: metabolic rate constrains the evolution of sperm size. Proceedings of the Royal Society B: Biological Sciences 278 3135-3141.

Guillette, L. J. Jr., Weigel, J. \& Flater, G. (1983). Unilateral testicular pigmentation in the Mexican lizard Sceloporus variabilis. Copeia 1983, 155-161.

Haerty, W., Jagadeeshan, S., Kulathinal, R. J., Wong, A., Ravi Ram, K., Sirot, L. K., Levesoue, L., Artieri, G. G., Wolfner, M. F., Civetta, A. \& SINGH, R. S. (2007). Evolution in the fast lane: rapidly evolving sex-related genes in Drosophila. Genetics 177, 1321-1335.

Haig, D. \& Bergstrom, C. T. (1995). Multiple mating, sperm competition and meiotic drive. Fournal of Evolutionary Biology 8, 265-282.

Harcourt, A. H., Harvey, P. H., Larson, S. G. \& Short, R. V. (1981). Testis weight, body weight and breeding system in primates. Nature 293, 55-57.

Hayakawa, Y. (2007). Parasperm: morphological and functional studies on nonfertile sperm. Ichthyological Research 54,111-130. 
Heinen, T. J. A. J., Staubach, F., Häming, D. \& Tautz, D. (2009). Emergence of a new gene from an intergenic region. Current Biology 19, 1527-1531.

Higginson, D. M. \& Pitnick, S. (2011). Evolution of intra-ejaculate sperm interactions: do sperm cooperate? Biological Reviews 86, 249-270.

Higginson, D. M., Miller, K. B., Segraves, K. A. \& Pitnick, S. (2012). Female reproductive tract form drives the evolution of complex sperm morphology. Proceedings of the National Academy of Sciences of the United States of America 109, 4538-4543.

Hodgson, A. N. (1997). Paraspermatogenesis in gastropod molluscs. Invertebrate Reproduction and Development 31,31-38.

Hosken, D. J. \& Stockley, P. (2004). Sexual selection and genital evolution. Trends in Ecology \& Evolution 19, 87-93.

Hosken, D. J. \& WARD, P. I. (2001). Experimental evidence for testis size evolution via sperm competition. Ecology Letters 4, 10-13.

IMMLER, S. (2008). Sperm competition and sperm cooperation: the potential role of diploid and haploid expression. Reproduction 135, 275-283.

IMMLER, S. \& BirkHEAD, T. R. (2007). Sperm competition and sperm midpiece size: no consistent pattern in passerine birds. Proceedings of the Royal Society B: Biological Sciences 274, 561-568.

IMMLER, S., CALHim, S. \& BiRKHEAd, T. R. (2008). Increased postcopulatory sexual selection reduces the intramale variation in sperm desion. Fvolution 62, 1538-1543.

Immler, S., Pryke, S. R., Birkhead, T. R. \& Griffith, S. C. (2010). Pronounced within-individual plasticity in sperm morphometry across social environments. Evolution 64, 1634-1643.

JANICKe, T. \& SCHÄRER, L. (2010). Sperm competition affects sex allocation but not sperm morphology in a flatworm. Behavioral Ecology and Sociobiology 64, 1367-1375.

Joly, D., Luck, N. \& Dejonghe, B. (2008). Adaptation to long sperm in Drosophila: correlated development of the sperm roller and sperm packaging. Fournal of Experimental Zoology Part B: Molecular and Developmental Evolution 310B, 167-178.

JosePh, S. \& KirkPATRICK, M. (2004). Haploid selection in animals. Trends in Ecology \& Evolution 19, 592-597.

KaEssmann, H. (2010). Origins, evolution, and phenotypic impact of new genes. Genome Research 20, 1313-1326.

Kerr, J. B., Loveland, M. K. \& O'Bryan, M. K. (2006). Cytology of the testis and intrinsic control mechanisms. In Knobil and Neill's Physiology of Reproduction. Third, (Chapter 18) Volume 1 Edition (eds J. D. Neill, T. M. Plant, D. W. Pfaff, J. R. G. Challis, D. M. De Kretser, J. S. Richards and P. M. Wassarman), pp. 827-947. Academic Press, Burlington.

KLEENE, K. C. (2005). Sexual selection, genetic conflict, selfish genes, and the atypical patterns of gene expression in spermatogenic cells. Developmental Biology 277, 16-26.

Klein, A. M., Nakagawa, T., Ichikawa, R., Yoshida, S. \& Simons, B. D. (2010). Mouse germ line stem cells undergo rapid and stochastic turnover. Cell Stem Cell $\mathbf{7}$, $214-224$.

Kleven, O., Laskemoen, T., Fossoy, F., Robertson, R. J. \& Lifjeld, J. T. (2008). Intraspecific variation in sperm length is negatively related to sperm competition in passerine birds. Evolution 62, 494-499.

LAMunYon, C. W. \& WARD, S. (1998). Larger sperm outcompete smaller sperm in the nematode Caenorhabditis elegans. Proceedings of the Royal Society of London. Series B: Biological Sciences 265, 1997-2002.

Levine, M. T., Jones, C. D., Kern, A. D., Lindfors, H. A. \& Begun, D. J. (2006). Novel genes derived from noncoding DNA in Drosophila melanogaster are frequently $\mathrm{X}$-linked and exhibit testis-biased expression. Proceedings of the National Academy of Sciences of the United States of America 103, 9935-9939.

Lewis, Z., Price, T. A. R. \& Wedell, N. (2008). Sperm competition, immunity, selfish genes and cancer. Cellular and Molecular Life Sciences 65, 3241-3254.

Long, T. A. F. \& Montgomerie, R. (2006). Ejaculate investment in a promiscuous rodent, Peromyscus maniculatus: effects of population density and social role. Evolutionary Ecology Research 8, 345-356.

Loppin, B., Lepetit, D., Dorus, S., Couble, P. \& Karr, T. L. (2005). Origin and neofunctionalization of a Drosophila paternal effect gene essential for zygote viability. Current Biology 15, 87-93.

Luders, E., Narr, K. L., Bilder, R. M., Szeszko, P. R., Gurbani, M. N., Hamilton, L., Toga, A. W. \& Gaser, C. (2008). Mapping the relationship between cortical convolution and intelligence: effects of gender. Cerebral Cortex 18, 2019-2026.

Luetjens, C. M., Weinbauer, G. F. \& Wistuba, J. (2005). Primate spermatogenesis: new insights into comparative testicular organisation, spermatogenic efficiency and endocrine control. Biological Revieres 80, 475-488.

Lüpold, S., Linz, G. M. \& BirkheAd, T. R. (2009a). Sperm design and variation in the New World blackbirds (Icteridae). Behavioral Ecology and Sociobiology 63, 899-909.

Lüpold, S., Linz, G. M., Rivers, J. W., Westneat, D. F. \& Birkhead, T. R. (2009b). Sperm competition selects beyond relative testes size in birds. Evolution 63, $391-402$.

Lüpold, S., Wistuba, J., Damm, O. S., Rivers, J. W. \& Birkhead, T. R. (2011). Sperm competition leads to functional adaptations in avian testes to maximize sperm quantity and quality. Reproduction 141, 595-605.

Manser, A., Lindholm, A. K., König, B. \& Bagheri, H. C. (2011). Polyandry and the decrease of a selfish genetic element in a wild house mouse population. Evolution 65, 2435-2447.
MCDaniel, M. A. (2005). Big-brained people are smarter: a meta-analysis of the relationship between in vivo brain volume and intelligence. Intelligence 33, 337-346. Mehlis, M., Frommen, J. G., Rahn, A. K. \& Bakker, T. C. M. (2012). Inbreeding in three-spined sticklebacks (Gasterosteus aculeatus L.): effects on testis and sperm traits. Biological Foumal of the Linnean Society 107, 510-520.

Miller, G. \& Pitnick, S. (2002). Sperm-female coevolution in Drosophila. Science 298, $1230-1233$.

Minoretti, N. \& BAUR, B. (2006). Among- and within-population variation in sperm quality in the simultaneously hermaphroditic land snail Arianta arbustorum. Behavioral Ecology and Sociobiology 60, 270-280.

M $\varnothing$ LLER, A. P. (1989). Ejaculate quality, testes size and sperm production in mammals. Functional Ecology 3, 91-96.

Møller, A. P. \& Cuervo, J. J. (2003). Sexual selection, germline mutation rate and sperm competition. BMC Evolutionary Biology 3, 6 .

Montgomerie, R. \& Fitzpatrick, J. L. (2009). Testes, sperm, and sperm competition. In Reproductive Biology and Phylogeny of Fishes (Agnathans and Bony Fishes), Part B (ed. B. G. M. Jamieson), pp. 1-53. Science Publishers Inc., Enfield.

Montoto, L. G., Arregui, L., Sanchez, N. M., Gomendio, M. \& Roldan, E. R. S. (2012). Postnatal testicular development in mouse species with different levels of sperm competition. Reproduction 143, 333-346.

Moore, P. J., Harris, W. E., Montrose, V. T., Levin, D. \& Moore, A. J. (2004). Constraints on evolution and postcopulatory sexual selection: trade-offs among ejaculate characteristics. Evolution 58, 1773-1780.

Moreira, J. R., Clarke, J. R. \& MacDonald, D. W. (1997a). The testis of capybaras (Hydrochoerus hydrochaeris). Fournal of Mammalogy 78, 1096-1100.

Moreira, J. R., MacDonald, D. W. \& Clarke, J. R. (1997b). Correlates of testis mass in capybaras (Hydrochaeris hydrochaeris): dominance assurance or sperm production? Journal of Zoology 241, 457-463.

Morrow, E. H. \& GAGE, M. J. G. (2001). Consistent significant variation between individual males in spermatozoal morphometry. Foumal of Zoology 254, 147-153.

Morrow, E. H., Leijon, A. \& Meerupati, A. (2008). Hemiclonal analysis reveals significant genetic, environmental and genotype x environment effects on sperm size in Drosophila melanogaster. Fournal of Evolutionary Biology 21, 1692-1702.

Narr, K. L., Woods, R. P., Thompson, P. M., Szeszko, P., Robinson, D., Dimtcheva, T., Gurbani, M., Toga, A. W. \& Bildoer, R. M. (2007). Relationships between IQ and regional cortical gray matter thickness in healthy adults. Cerebral Cortex 17, 2163-2171.

Normark, B. B. (2009). Unusual gametic and genetic systems. In Sperm Biology: An Evolutionary Perspective (eds T. R. Birkhead, D. J. Hosken and S. Pitnick), pp. 507-538. Academic Press, Burlington.

Nowak, M. A., Michor, F. \& Iwasa, Y. (2003). The linear process of somatic evolution. Proceedings of the National Academy of Sciences of the United States of America 100, $14966-14969$.

Nurminsky, D. I., Nurminskaya, M. V., De Aguiar, D. \& Hartl, D. L. (1998). Selective sweep of a newly evolved sperm-specific gene in Drosophila. Nature 396, $572-575$.

Olsson, M., Madsen, T. \& Shine, R. (1997). Is sperm really so cheap? Costs of reproduction in male adders, Vipera berus. Proceedings of the Royal Society of London. Series B: Biological Sciences 264, 455-459.

Oppliger, A., Hosken, D. J. \& RibI, G. (1998). Snail sperm production characteristics vary with sperm competition risk. Proceedings of the Roval Society of London. Series B: Biological Sciences 265, 1527-1534.

Parapanov, R., Nussle, S., Hausser, J. \& Vogel, P. (2008). Relationships of basal metabolic rate, relative testis size and cycle length of spermatogenesis in shrews (Mammalia, Soricidae). Reproduction, Fertility and Development 20, 431-439.

Parisi, M., Nuttall, R., Edwards, P., Minor, J., Naiman, D., Lü,J., Doctolero, M., Vainer, M., Chan, C., Malley, J., Eastman, S. \& Oliver, B. (2004). A survey of ovary-, testis-, and soma-biased gene expression in Drosophila melanogaster adults. Genome Biology 5, R40.

Parker, G. A. (1998). Sperm competition and the evolution of ejaculates: towards a theory base. In Sperm Competition and Sexual Selection (eds T. R. Birkhead and A. P. Møller), pp. 3-54. Academic Press, London.

Parker, G. A. \& Ball, M. A. (2005). Sperm competition, mating rate and the evolution of testis and ejaculate sizes: a population model. Biology Letters 1, 235-238.

Parker, G. A. \& Pizzari, T. (2010). Sperm competition and ejaculate economics. Biological Revieress 85, 897-934.

Parker, G. A., Ball, M. A., Stockley, P. \& Gage, M. J. G. (1996). Sperm competition games: individual assessment of sperm competition intensity by group spawners. Proceedings of the Royal Society of London. Series B: Biological Sciences 263, $1291-1297$.

Parker, G. A., Ball, M. A., Stockley, P. \& Gage, M. J. (1997). Sperm competition games: a prospective analysis of risk assessment. Proceedings of the Royal Society of London. Series B: Biological Sciences 264, 1793-1802.

Parker, G. A., Lessells, C. M. \& Simmons, L. W. (2013). Sperm competition games: a general model for precopulatory male-male competition. Evolution 67 , $95-109$. 
Peirce, E. J. \& Breed, W. G. (2001). A comparative study of sperm production in two species of Australian arid zone rodents (Pseudomys australis, Notomys alexis) with marked differences in testis size. Reproduction 121, 239-247.

Perry, J. G., Sirot, L. \& Wigby, S. (2013). The seminal symphony: how to compose an ejaculate. Trends in Ecology \& Evolution 28, 414-422.

Pitnick, S. (1996). Investment in testes and the cost of making long sperm in Drosophila. American Naturalist 148, 57-80.

Pitnick, S. \& Markow, T. A. (1994). Large-male advantages associated with costs of sperm production in Drosophila hydei, a species with giant sperm. Proceedings of the National Academy of Sciences of the United States of America 91, 9277-9281.

Pitnick, S., Markow, T. A. \& Spicer, G. S. (1995a). Delayed male maturity is a cost of producing large sperm in Drosophila. Proceedings of the National Academy of Sciences of the United States of America 92, 10614-10618.

Pitnick, S., Spicer, G. S. \& Markow, T. A. (1995b). How long is a giant sperm? Nature $\mathbf{3 7 5}, 109$.

Pitnick, S., Miller, G. T., Reagan, J. \& Holland, B. (2001). Males' evolutionary responses to experimental removal of sexual selection. Proceedings of the Royal Society B: Biological Sciences 268, 1071-1080.

Pitnick, S., Hosken, D. J. \& Birkhead, T. R. (2009). Sperm morphological diversity. In Sperm Biology: An Evolutionary Perspective (eds T. R. Birkhead, D. J. Hosken and S. Pitnick), pp. 69-149. Academic Press, Burlington.

Pizzari, T. \& Foster, K. R. (2008). Sperm sociality: cooperation, altruism, and spite. PLoS Biology 6, e130.

Pizzari, T., Dean, R., Pacey, A., Moore, H. \& Bonsall, M. B. (2008). The evolutionary ecology of pre- and post-meiotic sperm senescence. Trends in Ecology \& Evolution 23, 131-140.

Poinn, A. (2006). Complexity of seminal fluid: a review. Behavioral Ecology and Sociobiology 60, 289-310.

Presgraves, D. C. \& YI, S. V. (2009). Doubts about complex speciation between humans and chimpanzees. Trends in Ecology \& Evolution 24, 533-540.

Price, T. A. R., Hodgson, D. J., Lewis, Z., Hurst, G. D. D. \& Wedell, N. (2008). Selfish genetic elements promote polyandry in a fly. Science $322,1241-1243$

Qin, J., Calabrese, P., Tiemann-Boege, I., Shinde, D. N., Yoon, S.-R., Gelfand, D., Bauer, K. \& Arnheim, N. (2007). The molecular anatomy of spontaneous germline mutations in human testes. PLoS Biology $\mathbf{5}$, e224.

RACEY, P. A. (1979). The prolonged storage and survival of spermatozoa in Chiroptera. Journal of Reproduction and Fertility 56, 391-402.

Ramm, S. A. \& Stockley, P. (2009). Adaptive plasticity of mammalian sperm production in response to social experience. Proceedings of the Royal Society B: Biological Sciences 276, 745-751.

Ramm, S. A. \& Stockley, P. (2010). Sperm competition and sperm length influence the rate of mammalian spermatogenesis. Biology Letters 6, 219-221.

ReInHARDT, K. (2007). Evolutionary consequences of sperm cell aging. The Quarterly Review of Biology 82, 375-393.

Reinke, V., Smith, H. E., Nance, J., Wang, J., Van Doren, G., Begley, R., Jones, S. J., Davis, E. B., Scherer, S., WArd, S. \& Kim, S. K. (2000). A global profile of germline gene expression in C. elegans. Molecular Cell 6, 605-616.

Ribble, D. O. \& Millar, J. S. (1992). Intraspecific variation in testes size among Northern populations of Peromyscus. Functional Ecology 6, 455-459.

Roosen-Runge, E. C. (1977). The Process of Spermatogenesis in Animals. Cambridge University Press, Cambridge.

Rowe, M. \& PruetT-Jones, S. (2011). Sperm competition selects for sperm quantity and quality in the Australian Maluridae. PLoS one 6, e15720.

Russell, L. D., Ren, H. P., Sinha Hikim, I., Schulze, W. \& Sinha Hikim, A. P. (1990). A comparative study in twelve mammalian species of volume densities, volumes, and numerical densities of selected testis components, emphasizing those related to the Sertoli cell. The American fournal of Anatomy 188, 21-30.

Schärer, L. \& LAdurner, P. (2003). Phenotypically plastic adjustment of sex allocation in a simultaneous hermaphrodite. Proceedings of the Royal Society B: Biological Sciences 270, 935-941.

SCHÄrer, L. \& Vizoso, D. B. (2007). Phenotypic plasticity in sperm production rate: there's more to it than testis size. Evolutionary Ecology 21, 295-306.

Schärer, L., Ladurner, P. \& Rieger, R. M. (2004). Bigger testes do work more: experimental evidence that testis size reflects testicular cell proliferation activity in the marine invertebrate, the free-living flatworm Macrostomum sp. Behavioral Ecology and Sociobiology 56, 420-425.

Schärer, L., Zaubzer, J., Salvenmoser, W., Seifarth, C. \& Ladurner, P. (2007). Tracking sperm of a donor in a recipient: an immunocytochemical approach. Animal Biology 57, 121-136.

Schärer, L., DA LAGE, J.-L. \& Joly, D. (2008). Evolution of testicular architecture in the Drosophilidae: a role for sperm length. BMC Evolutionary Biology 8, 143.
Schärer, L., Littlewood, D. T. J., Waeschenbach, A., Yoshida, W. \& Vizoso, D. B. (2011). Mating behavior and the evolution of sperm design. Proceedings of the National Academy of Sciences of the United States of America 108, 1490-1495.

SHinn, G. L. (1997). Chaetognatha. In Microscopic Anatomy of Invertebrates, Volume 15: Hemichordata, Chaetognatha, and the Invertebrate Chordates, pp. 103-220. Wiley-Liss, New York.

SHort, R. V. (1979). Sexual selection and its component parts, somatic and genital selection, as illustrated by Man and the Great Apes. Advances in the Study of Behavior $\mathbf{9}$, $131-158$

Simmons, L. W. \& Fitzpatrick, J. L. (2012). Sperm wars and the evolution of male fertility. Reproduction 144, 519-534.

Simmons, L. W. \& Garcia-GonZalez, F. (2008). Evolutionary reduction in testes size and competitive fertilization success in response to the experimental removal of sexual selection in dung beetles. Evolution 62, 2580-2591.

Simmons, L. W. \& Moore, A. J. (2009). Evolutionary quantitative genetics of sperm. In Sperm Biology: an Evolutionary Perspective (eds T. R. Birkhead, D. J. Hosken and S. Pitnick), pp. 405-434. Academic Press, Burlington.

Smith, C. \& Wootton, R. (2005). Parental energy expenditure of the male threespined stickleback. Fournal of Fish Biology 54, 1132-1136.

Stocco, D. M. \& McPhaul, M. J. (2006). Physiology of testicular steroidogenesis. In Knobil and Neill's Physiology of Reproduction. Third, Chapter 32 (Volume 1, eds Edition (eds J. D. Neill, T. M. Plant, D. W. Pfaff, J. R. G. Challis, D. M De Kretser, J. S. Richards and P. M. Wassarman), pp. 977-1016. Academic Press, Burlington.

Stockley, P. \& SeAL, N. J. (2001). Plasticity in reproductive effort of male dung flies (Scatophaga stercoraria) as a response to larval density. Functional Ecology 15, 96-102.

Swallow, J. G. \& Wilkinson, G. S. (2002). The long and short of sperm polymorphisms in insects. Biological Reviewes 77, 153-182.

Swanson, W. J. \& Vacquier, V. D. (2002). The rapid evolution of reproductive proteins. Nature Reviewes Genetics 3, 137-144.

TAN, G. N., Govedich, F. R. \& Burd, M. (2004). Social group size, potential sperm competition and reproductive investment in a hermaphroditic leech, Helobdella papillomata (Euhirudinea: Glossiphoniidae). Fournal of Evolutionary Biology 17, 574-580.

Turner, L. M. \& Hoekstra, H. E. (2008). Causes and consequences of the evolution of reproductive proteins. The International Fournal of Developmental Biology 52, 769-780.

Vermeulen, A., Engels, S., Engovist, L. \& Sauer, K. P. (2009). Phenotypic plasticity in sperm traits in scorpionflies (Mecoptera: Panorpidae): consequences of larval history and seasonality on sperm length and sperm transfer. European fournal of Entomology 106, 347-352.

Vibranovski, M. D., Chalopin, D. S., Lopes, H. F., Long, M. \& Karr, T. L. (2010). Direct evidence for postmeiotic transcription during Drosophila melanogaster spermatogenesis. Genetics 186, 431-433.

WARD, P. I. (1998). Intraspecific variation in sperm size characters. Heredity 80 , $655-659$.

WEDELL, N. (2013). The dynamic relationship between polyandry and selfish genetic elements. Philosophical Transactions of the Royal Society, B: Biological Sciences 368 20120049 .

Werren, J. H. (2011). Selfish genetic elements, genetic conflict, and evolutionary innovation. Proceedings of the National Academy of Sciences of the United States of America 108(Suppl. 2), 10863-10870.

White-Cooper, H. \& Bausek, N. (2010). Evolution and spermatogenesis. Philosophical Transactions of the Royal Society, B: Biological Sciences 365, 1465-1480.

White-Cooper, H., Doggett, K. \& Ellis, R. (2009). The evolution of spermatogenesis. In Sperm Biology: An Evolutionary Perspective (eds T. R. BirkHEAD, D. J. Hosken and S. Pitnick), pp. 151-183. Academic Press, Burlington.

Wilson Sayres, M. A. \& Makova, K. D. (2011). Genome analyses substantiate male mutation bias in many species. Bioessays 33, 938-945.

Wilson Sayres, M. A., Venditti, C., Pagel, M. \& Makova, K. D. (2011). Do variations in substitution rates and male mutation bias correlate with life-history traits? A study of 32 mammalian genomes. Evolution 65, 2800-2815.

Wistuba, J., Schrod, A., Greve, B., Hodges, J. K., Aslam, H., Weinbauer, G F. \& Luetjens, C. M. (2003). Organization of seminiferous epithelium in primates: relationship to spermatogenic efficiency, phylogeny, and mating system. Biology of Reproduction 69, 582-591.

YoshidA, S. (2012). Elucidating the identity and behavior of spermatogenic stem cells in the mouse testis. Reproduction 144, 293-302.

Zbinden, M. (2001). Sperm allocation in the three-spined stickleback. Fournal of Fish Biology 59, 1287-1297.

Zieri, R., Taboga, S. R. \& de Oliveira, G. (2007). Melanocytes in the testes of Eupemphix nattereri (Anura, Leiuperidae): histological, stereological, and ultrastructural aspects. The Anatomical Record 290, 795-800.

(Received 16 April 2013; revised 23 December 2013; accepted 12 January 2014; published online 3 February 2014) 